\title{
TEACHING FOR BETTER LEARNING
}

\author{
JB BIGGS*
}

\section{INTRODUCTION}

Large and small classes, lectures and discussions, and other comparisons of teaching show few consistent and significant differences. The conclusion that teaching doesn't make a difference is, however, erroneous. ${ }^{1}$ Research into tertiary teaching and learning is moving from a deficit or "blame" model, to one that attempts to coordinate the whole context of teaching. We should be seeking less to eradicate defects in students, or to search for "best" methods of teaching, or to remove poor teachers by appraisals that sour the context for good teachers as well, but rather to encourage staff to reflect upon what they already do to help students learn, to see how they can do it better. In particular, we need to change staff conceptions of teaching and learning, and to increase staff awareness of the relationship between teaching procedures, learning activities, and learning outcomes.

\section{CONCEPTIONS OF LEARNING AND TEACHING}

Let us start with how teachers (and students) conceive learning and teaching. For example, if teachers believe that their task is to transfer information from one skull to another, they are unlikely to use other than expository teaching methods. Their beliefs or conceptions of learning need to be changed.

There are in fact several such conceptions of learning and teaching:

\section{Quantitative}

(a) Learning is a matter of how much is learned. There are a few variations within the quantitative conception: from learning as a vague "knowing more", through learning as defined by 
accurate reproduction, to learning as "coverage” of a list of the facts, skills, concepts and principles that need to be known. ${ }^{2}$ The last is quite a sophisticated view, which often guides curriculum design. Undoubtedly, one can list items that "need to be known", but in this conception they remain as declarative or "book" knowledge, which may not impinge on real world interaction.

(b) Teaching is a transmission process. Many teachers, especially beginning teachers, see their task as one of transmitting knowledge that emanates from an external source. A good teacher here needs only to know his or her subject, and to communicate that knowledge fluently. This conception pervades official thinking in Third World educational systems, ${ }^{3}$ but although the rhetoric in Australia has moved from that position, the actuality frequently hasn't:

The typical view of the tertiary teacher has been that of didactic lecturer. The traditional mode of instruction has been that of the one person talking and the many listening... students perceive their role as passive listeners and recorders of the lecture content (who) write much and understand little. ${ }^{4}$

\section{Institutional}

1 Learning has to be taught and evaluated in an institution of learning. The evidence that learning has occurred is that a course has been passed: the higher the grade, the better the learning. While the principles of compulsory schooling and accreditation requires that learning be managed by professionals, the means in this conception becomes the end; teaching and its management overshadow learning. Nowhere is this more evident than in the area of assessment, where management requirements determine assessment decisions, often to the detriment of good learning. ${ }^{5}$

2 Teaching is the efficient orchestration of teaching skills. Teachers with this conception see good teaching as effective management of teaching resources. Staff development thus involves enhancing the range and effectiveness of one's use of teaching techniques. The danger here is that the focus is mainly or solely on what teachers do, not what students do. 


\section{Qualitative}

1 Learning involves personal meaning: a way of understanding experience. Many tertiary teachers see their discipline as involving particular qualities of thinking and problem solving, and want their students to acquire that way. ${ }^{6}$ This is particularly true in professional faculties, where there is a clear split between the declarative knowledge of the cognate disciplines, and the procedural knowledge underlying good practice, so that the integration of practicum with coursework becomes a major problem. ${ }^{7}$ Learning is not only acquiring knowledge, but using and reinterpreting knowledge, and seeing the world in a different way. Others may help or "scaffold" this process, but they can't take it over.

2 Teaching helps the learner restructure experience. The role of the teacher thus changes radically in this conception, from one who transmits extant knowledge to one who interacts with the student in ways that will encourage students to construct their own knowledge appropriately. In this conception, teaching is just such a scaffolding process; the point is to find what ways will work within the context one has to deal with.

\section{THE CLASSROOM ECOSYSTEM}

The major components in classroom learning can be placed in a systematic relationship, as outlined in Figure 1. The three main components - presage, process, and product (hence the "3P" model) - form a system, with interaction between all components, only some of which are illustrated in Figure 1. In the ecology of a system, a change to any one component will have effects throughout, but if the rest of the system is resistant to change, then that one component will not change either. This has to be remembered when trying to improve learning, a point I return to later.

Presage factors exist prior to learning, and relate to the student, and to the teaching context: I concentrate on the latter here. The teaching context contains factors many of which are under the teacher's or the institution's control: some teacher characteristics, course structure and content, methods of teaching and assessment, 
and the rules and routines that govern institutional life. These and other factors also generate a climate for learning, which has important motivational consequences. The improvement of learning involves focusing on the total teaching context, and its cognitive and affective impacts on students. Students interpret this teaching context in the light of their own preconceptions and motivations, thereby deriving their particular approach to the task in question. The issue of how students approach the particular tasks they arc set, i.e. the extent to which they use rote memorisation or higher cognitive processes, is located at this stage; the terms “deep” and "surface” have been widely used in this context. An important key to call out desired approaches is through motivation.

Following the conceptions of teaching and learning, the product of learning may likewise be described quantitatively (how much is learned), qualitatively (how well it is learned), and institutionally (which draws variously on both, in the constitution of the grades awarded). Effective outcomes relate to how students feel about their learning, efficacy beliefs being one example, which are crucial in determining the quality and extent of their future involvement in learning. In line with the systems model, interaction proceeds at all levels. At presage, students conceptions of learning and teaching may be changed by what they see of the teaching context, while teachers' perceptions of student's abilities or interests will, or should, affect their decision-making. Likewise, students' perceptions of outcome will determine inter alia their beliefs about their own efficacy; if students believe or are led to believe they are not competent, they will not be motivated in future. Likewise, teachers' efficacy beliefs are a major point of inflection for staff development; they too need to be led into believing their own competence, an unlikely outcome under harsh or unimaginative staff appraisal systems.

Outcomes, according to the model, are however in large part determined by approaches, so that an important part of teaching is to optimize the chances that the most adaptive approaches to learning are utilized.

\section{Approaches to Learning}

An approach to learning comprises a motive and a related strategy; that is, what you want out of learning will determine how 
you go about learning. If a student is motivated by curiosity, and seeks to allay that curiosity by rote learning, there is a lack of congruence between motive and strategy that indicates poor selfknowledge. Three approaches, and their cognate motives and strategies, are given in Table l:

Table 1: Three Prototypical Approaches to Learning

\begin{tabular}{|c|c|c|}
\hline \multicolumn{3}{|c|}{ Approach } \\
\hline & Motive & Strategy \\
\hline Surface & $\begin{array}{l}\text { Extrinsic: Avoid Focus } \\
\text { on selected failure but } \\
\text { don't work too hard }\end{array}$ & $\begin{array}{l}\text { Focus on selected details } \\
\text { and reproduce accurately }\end{array}$ \\
\hline Deep & $\begin{array}{l}\text { Intrinsic: Satisfy } \\
\text { curiosity about topic }\end{array}$ & $\begin{array}{l}\text { Maximise understanding: } \\
\text { read widely, discuss, } \\
\text { reflect }\end{array}$ \\
\hline Achieving & $\begin{array}{l}\text { Achievement: Compete } \\
\text { for highest grades }\end{array}$ & $\begin{array}{l}\text { Optimise organization of } \\
\text { time and effort ("study } \\
\text { skills") }\end{array}$ \\
\hline
\end{tabular}

The term "strategy" in Table 1 is used in a general sense. The specific cognitive strategies used in handling a particular task will depend on the task in question; and whether it is deep or surface depends, apart from the relevant content knowledge, on two factors:

- the process appropriate to the particular stage of carrying out the task, and

- the level of abstraction of the unit thus processed.

In essay writing, for instance, the processes may include: planning, updating knowledge, composing, transcribing, reviewing and revising; and the level of abstraction on whether the writer is currently focusing on word, phrase, sentence, paragraph or theme.

Surface strategies focus on quick returns that satisfice, rather than satisfy, the task demands. In writing, attention is focused during these activities on the level of ideational complexity no higher than that contained in a sentence. Sentences thus tend to be linked in a linear sequence (eg chronological or narrative), which is inappropriate for most academic purposes. ${ }^{8}$ In reading from text, and in note-taking, attention is focused likewise on sentence-length ideas, or less, the simplest form of note-taking being “copy-delete”, where some phrases and sentences are simply transcribed, and others omitted. At this surface level, there is no transformation of 
key phrases into conceptually richer semantic units. 


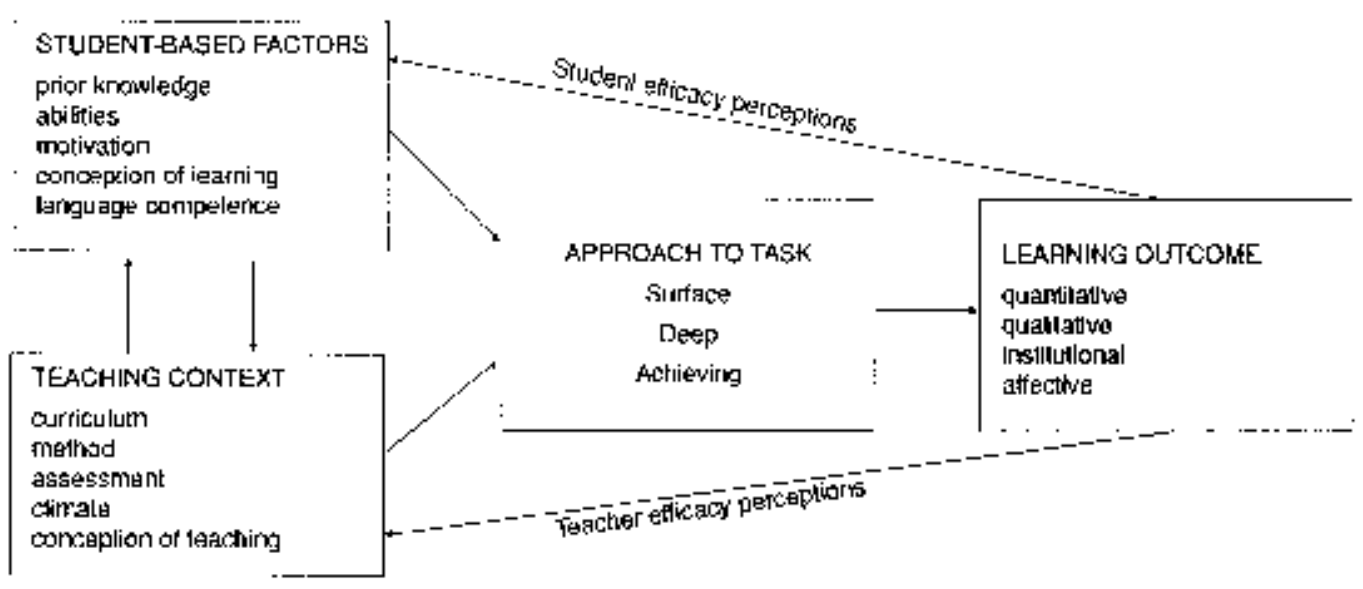


Deep strategies require activities that integrate detail and high level ideation. In writing, the detail in an ill-set sentence can be cutand-pasted to the appropriate context, or deleted; in both cases, the decision is embedded in high level or thematic thinking, whereas surface revision strategies go no further than adding text, which requires only sentence level thinking.

Relationships between such approaches and outcome are exceptionally strong: studies in history, computer studies, reading, and writing show that a surface approach, almost without exception, leads to a quantitative outcome of unstructured detail, and a deep approach to an appropriately structured outcome. ${ }^{9}$ Such findings suggest very clearly that the thrust of teaching should be to engage the learner in deep approaches to learning and problemsolving.

Achieving strategies, unlike deep and surface, do not engage the task content, but the temporal and spatial context in which the task is placed; they involve cost-effective planning and use of time and space, as in the traditional approach to study skills training. Achieving strategies can be linked to either surface or deep, so that one can rote learn, or seek meaning, with optimum deployment of time and effort.

This model thus suggests some ways of inducing more effective learning. Surface approaches lead generally to undesirable, and deep and achieving to desirable, outcomes. The implication is clear. Good teaching should minimize those factors that lead to the surface approach, and maximize those that lead to both deep and achieving approaches. I have dealt with the general implications for teaching and skill training elsewhere. ${ }^{10}$ My main focus is on one aspect that dominates approaches both to teaching and to learning: the question of motivation, the precursor to appropriate strategy use. I then turn to the teaching context.

\section{THE MOTIVATIONAL CONTEXT}

Motivation not only moves behaviour, it directs it. How you go about a task depends on what you want out of it; strategy is embedded in motive. If we wish to improve students' learning strategies, then, the place to start is with students' motives.

Although both teaching context and student's characteristics jointly determine students' immediate intentions of task 
engagement, their contributions vary; it is unfortunately easier to induce a surface than a deep approach. A surface approach is a reaction to external stipulations, communicated via the teaching context, while a deep approach is internally controlled, describing the way a student creates meaning, in terms of the structure the student can bring to the task. It is very easy to make students anxious, cynical, or simply overworked - all excellent soil for surface strategies to flourish — but much more difficult to make them curious. A few, excellent, teachers can do this; indeed, the ability to do so is crucial to any definition of good teaching. Many more teachers find it much easier, all too frequently in accordance with institutional demands, to create a context of busywork, so that students' top priorities are to meet the letter of the demands made on them, and to defend against negative judgment.

As to diminishing surface motives, there is a wealth of evidence on what practices encourage surface approaches to learning. ${ }^{11}$ Such practices include: overwork, assessment practices emphasising recall of detail (of which there is a vast range, and which probably more than anything accounts for surface learning), stress (both in the sense of time pressure and interpersonal friction between teacher and student), and the induction of cynicism, for example by rewarding form rather than content in evaluating assignments, by devaluing the topic when teachers express their own dislike/contempt for the topic, and by highlighting the trivial.

Some of these factors may be pin-pointed by a well designed questionnaire eliciting students' and colleagues' perceptions, ${ }^{12}$ and with self-insight and some honesty, may be removed. Others are very subtle; yet others are almost ineradicable given the way most institutions are run. To become aware of all these inhibitors of good learning in one's teaching involves a personal and an institutional self-searching that might be painful, and while it may not be very practical to eliminate them all, there is no doubt that much progress can be made along these lines.

As to increasing academic motivation, a broader approach than seeing the task as only one of creating interest, the classic precursor of the deep strategy, might be helpful. Such an approach is contained in the expectancy-value model of motivation, which states that the felt need to behave is a joint function of the value to the individual of the act, and its likelihood of success: if anyone is 
to engage an activity, they need to expect some valued outcome. ${ }^{13}$ Few are moved by the pot of gold at the end of an impossible rainbow; few, likewise, by the easy capture of the paltry. A particular action needs both to be associated with something personally valued, and to stand a reasonable chance of success. Not valuing success, or not expecting success however valued, will leave the student unmoved. Both value and expectancy need to be high.

This leaves the teacher with two tasks:

1 to help students value what they are doing,

2 to give them a reasonable expectation of success.

\section{VALUE}

What is that enhances the value of academic learning to the student? Undoubtedly, the intellectual passion of intrinsic motivation is the ideal. Educational thinkers universally involve excellent teaching with the creation of intrinsic motivation. A large part of this process is epidemiological; teachers make their passion contagious. How they do this is in part personal and nonreplicable, but two factors otherwise stand out: the cognitive dynamics of task engagement, and the affective context of task ownership.

Cognitively, intrinsic motivation arises when there is an optimal mismatch between level of difficulty of the task and the individual's current competence; a mismatch affected by the pacing of the task, the knowledge base possessed by the student for processing the task, and continuing feedback from outcomes. As pace, knowledge base, and reaction to feedback are individual, achieving optimal mismatch may be seen as simply impractical. In the lecture room it usually is (to all but very skilful lecturers), but in small group or individually paced instructional episodes, it is possible to achieve optimal pacing: two outstanding examples being particular forms of small groups ${ }^{14}$ and problem-based learning. ${ }^{15}$ The interaction induced in such situations has several features that promote optimal processing:

- a high level of activity; students are less likely to remain passive in well run groups.

- students provide each other with immediate feedback, at a level they can readily encode.

- students are more likely to be evenly paced in their respective 
processing capabilities, so that interaction is always engageable.

- in both groups and problem based learning, students are placed in a context providing a felt need to respond: group expectations and a genuine problem demanding solution, respectively.

Affectively, intrinsic motivation is summed up as ownership, and as a felt need to respond. Students feel a need to respond to what they perceive as peculiarly "theirs": an argument, a position, a responsibility, identification with a career-related step, with the public recognition that endorses ownership. Ownership can be encouraged by almost anything that opens out individual choice; for electives, assignment topics, at the obvious level, to class acknowledged expertise in some particular area, arising from some unpredictable interaction. Ownership can be established and expressed in quite subtle ways in student-teacher, interaction: a comment over an essay or in conversation. This feeling, if it can be established, is one that obviously brings high personal value to a task, although what it is that will make students value their academic tasks more differs from course to course and from teacher to teacher.

\section{EXPECTANCY}

Students need to expect success: to believe that there is point in going on. One factor here is perceived self-competence; in particular, in how competent students believe they are in quite specific task domains. Students arrive at these self-perceptions in several ways. Perception of outcome is one important way (see Figure 1, "efficacy beliefs"); teacher communications another. The following came out in an interview I once had with a potential research assistant, who was just finishing her degree as a mature age student:

I'd already had several children before coming to Uni, and I wasn't sure how I could handle it. I was really interested in psychology, but when we got to the Psych I Lectures, the Stats lecturer said, "Anyone who can't follow this isn't fit to be at University ... “ That was the first message I got. I was having difficulty with stats and so I thought ... maybe Uni isn't for me. I liked the rest of Psych. but couldn't handle the stats and had to withdraw. Next year, funny thing, I did Maths I ... probability theory, much the same stuff that I had bombed out in last year. But the lecturer there was a woman and maybe she understood better the difficulties many women have, or anyone, come to that, and she said, "Probability is quite hard really. You'll need to work at it. 
You're welcome to come to me for help if you really need it.” It was like a blinding light. It wasn't me after all! This stuff really was hard, but if I tried it might just work. That year I got a credit in that part of the subject.

Apart from illustrating just how crass some teachers can be, it also illustrates how attributions for success and failure can affect motivation; why students believe they fail or succeed. Attributing success to effort, and to instrumental skills that may readily be acquired such as study skills, creates a heightened expectancy of success, whereas attributing success to ability only does if you believe yourself particularly bright, relative to the kind of task in question.

Another important factor in expecting success is task difficulty. An unfortunate initial history, or macho self-justifications from lecturers, can convey to students the belief that the task is harder than it is. Initial goal-setting is therefore quite crucial, so that students build up a belief in their self-efficacy: without such a belief, further learning is doomed.

\section{THE TEACHING CONTEXT}

The best answer to the question, "What is the most effective method of teaching?”, is that it depends on the goal, the student, the content, and the teacher. But the next best answer is, "Students teaching other students.” There is a wealth of evidence that peer teaching is extremely effective for a wide range of goals, content, and students of different levels and personalities. ${ }^{16}$

So the answer is that while there are no single best method of teaching, some methods are better than others. Better teaching methods are those that are more effective in getting the learner to engage in productive learning activities. Peer teaching is one, ${ }^{17}$ and as we have noted, student interaction in general and problem based learning are definitely others. The thrust here, however, is not the adoption of particular techniques and methods, but to reflect on teaching; each teacher needs to reflect on his or her own context. Their question should not be:

- "Tell me what to do in order to motivate my students" but:

- 'What messages am I conveying to my students, in presentation, assessment and general interaction with them, about the value of the tasks and their expectations of success? What limitations are there if I want to change my procedures?” 
Teachers, like students, need both to develop their own efficacy beliefs, and to arrive at a qualitative conception of teaching and learning. Studies over many institutions and years have drawn attention to the wide gap between the rhetoric describing the qualities lecturers say they want in their students' responses, and the tasks they, set, which frequently are most successful at eliciting question-spotting and rote memorisation of facts and theories considered important by the teachers. ${ }^{18}$ Challenging teachers' beliefs directly won't work; quite simply, they believe their conceptions are "right" already. Facing them with changed learning outcomes, however, is likely to challenge their existing beliefs and may bring about permanent change. As it is, teachers are mostly aware of student learning outcomes in the form of scores on tests of declarative knowledge, which do not necessarily reflect qualitative understandings, particularly if they are further obfuscated by normreferencing. When teachers are provided with feedback on students' qualitative understandings, they are often quite shocked by the mismatch between their beliefs as to what students have learned and the actuality; this is a technique used by Bowden ${ }^{19}$ to bring about change in tertiary teachers in workshops.

\section{THE INSTITUTIONAL CONTEXT}

Finally, I have to mention the institutional context. If its macrodecisions are couched in a quantitative conception, the teachers within the institution will be likely to absorb that conception. The superordinate system is the one that best calls the shots.

One of the biggest problems in improving learning is institutional. Institutions frequently appear to undermine their own espoused aims. For example, undergraduates not intending to continue on to postgraduate study drop deep and achieving approaches alarmingly. ${ }^{20}$ Institutionalising learning often emphasises the inessentials, the enabling activities. Getting a presentable assignment in by the deadline is institutionally more important (and therefore existentially to the student) than spending time on an excellent one. Thus, despite teachers' best intentions, they are often forced into creating and maintaining a context that requires students to focus on form rather on substance: on meeting requirements rather than on excellence of content. Factors 
especially powerful in achieving this are out of teachers' hands: examination regulations, prerequisites, time exigencies, and most importantly in professional faculties, the imposition of too high a workload, which they and others see as demanded by accreditation requirements of outside bodies.

It is important to understand this if we are interested in redesigning learning contexts; such redesigning needs to balance what is officially wanted, what is technically possible in the circumstances of that institution, and what has evolved so far through consensus amongst colleagues.

This last factor, the social system, often has a greater effect on classroom practice than the official aims of the system. It comprises such things as resource allocation, rules and routines, administrative structures, industrial stipulations, and the expectations and norms of colleagues and students, and to which teachers are expected to conform. Twenty years ago (and until two years ago in my present institution), it was policy in many British universities not to reveal grades to students, clearly not for educational reasons, but because it made life easier for lecturers; for it to work, all had to agree. There are hundreds of such examples where tradition, habit and convenience hinder enlightened change. The remedy, ultimately, can only be honest reflection on an institutional basis, although that process may need to be sparked off by the more sociopathic of the potential innovators.

\section{CONCLUSIONS}

Recent research into how students go about learning has important implications for improving tertiary teaching. Classroom learning takes place in an interactive ecosystem, in which all components affect each other. Students adopt qualitatively different approaches to learning, depending in large part on how they react to that ecosystem (and are part of it).

An important lever on good learning is through motivation. The expectancy-value model provides a framework for motivating students and for structuring the task and context so that students are most likely to acquire appropriate strategies for learning. Several ways are described in which students can be helped to value the tasks they are required to do, and to perceive that they have a 
reasonable chance of meeting those requirements. If they do not value the task or do not expect success, they will be turned off learning, and adopt low level surface strategies that may suffice to get by, but will not meet the requirements of professional training.

However, the teacher is often caught between knowledge of what fosters good learning as far as the student is concerned, and what is possible within the context of the institution. Improved learning is most likely through a reflective approach to staff development rather than through the adoption of particular teaching techniques.

* Department of Education, University of Hong Kong. This article is based on Keynote Discussion Paper, Annual Conference, Higher Education Research and Development Society of Australia, 6-9 July, 1990, Griffith University, Brisbane. (C) 1991. (1990-91) 2 Legal Educ Review 133.

1 WJ McKeachie, P Pintrich, Y-G Lin \& D Smith, Teaching and Learning in the College Classroom (University of Michigan: NCRIPTAL, 1986) at 63.

2 F Marton \& R Saljo, Approaches to Learning in F Marton, D Hounsell \& N Entwistle (eds), The Experience of Learning (Edinburgh: Scottish UP, 1984).

3 C Beeby, The Quality of Education in Developing Countries (Cambridge Massachusetts: Harvard UP, 1966).

4 A Radloff \& J Samson, Promoting Intelligent Behaviour in Students: The Role of the Tertiary Teacher. Paper presented at Seminar on Intelligence Australian Council for Educ Research, Melbourne 24-26 August 1988 at 4.

5 TJ Crooks, The Impact of Classroom Evaluation Practices on Students (1988) 58 Rev of Educ Research 438.

$6 \quad$ N Entwistle, Contrasting Perspectives on Learning, in F Marton, D Hounsell \& N Entwistle (eds) The Experience of Learning (Edinburgh: Scottish UP, 1984).

7 J Biggs, Institutional Learning and the Integration of Knowledge, in J Balla \& M Gibson (eds) Learning in Medical School (Hong Kong: University of Hong Kong Press, 1989).

8 J Biggs, Process and Outcome in Essay Writing (1987) 9 Research and Dev in Higher Educ 114.

9 Id; F Marton \& R Saljo, On Qualitative Differences in Learning - I: Outcome and Process (1976) 46 Brit J of Educ Psychology 4; EJ Van Rossum \& SM Schenk, The Relationship Between Learning Conception, Study Strategy and Learning Outcome (1984) 54 Brit J of Educ Psychology 73; DA Watkins, Depth of Processing and the Quality of Learning Outcomes (1 983) 12 Instructional Sci 49.

10 J Biggs, Approaches to the Enhancement of Tertiary Teaching (1989) 8 Higher Educ Research and Dev 7.

11 TJ Crooks, The Impact of Classroom Evaluation Practices on Students (1988) 58 Review of Educ Research 438; P Ramsden, The Context of Learning in F Marton, D Hounsell \& N Entwistle (eds) The Experience of Learning (Edinburgh: Scottish Academic Press, 1984); P Ramsden, Student Learning Research: Retrospect and Prospect (1985) 5 Higher Educ Research and Dev 51.

12 P Ramsden \& A Dodds, Improving Teaching and Courses: A Guide to Evaluation (University of Melbourne: Centre for the Study of-Higher Education, 1989).

13 N Feather (ed), Expectations and Actions (Hillsdale NJ: Erlbaum, 1982). 
14 KG Collier, Teaching Methods in Higher Education: The Changing Scene, with Special Reference to Small Group Work (1985) 4 Higher Educ Research and Dev 3; M Johnson Abercrombie, The Anatomy of Judgment (Harmondsworth Mdx: Penguin Books, 1969).

D Boud, Problem-Based Learning in Education for the Professions (Sydney: Higher Education Research and Development Society of Australasia, 1985).

16 McKeachie et al supra note 1.

17 D Johnson, G Maruyama, R Johnson, D Nelson \& L Skon, The Effects of Cooperative, Competitive and Individualistic Goal Structures on Achievement: A Meta-Analysis (1981) 89 Psychological Bull 47.

$18 \mathrm{~J}$ Bowden, Achieving Change in Teaching Practice, in P Ramsden (ed) Improving Learning: New Perspectives (London: Kogan Page, 1988); Entwistle supra note 6; Ramsden supra note 11.

19 Id.

20 JB Biggs, Student Motivation and Study Strategies in University and CAE Populations (1982) 1 Higher Educ Research and Dev 33; MJ Stokes, JR Balla \& KJ Stafford, How Students in Selected Degree Programmes at CPHK Characterise their Approaches to Study (1989) 4 Educ Research J 85; DA Watkins \& JA Hattie, Longitudinal Study of the Approach to Learning of Australian Tertiary Students (1985) 4 Hum Learning 127. 